\title{
Estimation of the Terceira Island (Azores) main strain rates from GPS data
}

\author{
Ana Navarro ${ }^{1}$, João Catalão ${ }^{1}$, Jorge Miguel Miranda ${ }^{2}$, and Rui Manuel Fernandes ${ }^{3,4}$ \\ ${ }^{1}$ Department of Mathematics, Faculty of Sciences, University of Lisbon, Portugal \\ ${ }^{2}$ CGUL, Faculty of Sciences, University of Lisbon, Portugal \\ ${ }^{3}$ Delft Institute for Earth-Oriented Space Research, TU Delft, Kluyverweg 1, 2629 HS Delft, Netherlands \\ ${ }^{4}$ Department of Computer Science, University of Beira Interior, Covilhã, Portugal \\ (Received May 6, 2003; Revised October 20, 2003; Accepted October 20, 2003)
}

\begin{abstract}
The nature and location of the present EUR/AFR boundary configuration in the Azores region is controversial and, in particular, the pattern of the present day deformation associated with plate boundary processes, is still unknown. We present here GPS data from 10 stations, in a segment of this boundary (Terceira Island), where data at 2 epochs (1999 and 2001) are available. GPS data were processed using GAMIT and FONDA, with horizontal position repeatability circa $3 \mathrm{~mm}$ and $2 \mathrm{~mm}$, respectively, for 1999 and 2001 epochs. Stations horizontal displacements range from 0.96 to $4.60 \mathrm{~mm} / \mathrm{yr}$. Strain analysis indicates compression for four sub-networks. The rates of local rotation are consistent for three sub-networks on the western part of Terceira, exhibiting a clockwise rotation of about $8^{\circ}$ per million years. Although they are still preliminary, these results are discussed in relation with the expected behaviour from regional geodynamic constraints and past geodetic studies.
\end{abstract}

Key words: Azores triple junction, crustal deformation, GPS, Terceira Island.

\section{Introduction}

West of Gibraltar, the western segment of the Eurasian/African (EUR/AFR) plate boundary, is mainly of the transform type, following a prominent morphological signature - the Gloria Fault (Fig. 1). From the western tip of Gloria fault to the Mid-Atlantic Ridge (MAR), this boundary is more elusive, but seismicity (Udias et al., 1976; Grimison and Chen, 1986, 1988; Buforn et al., 1988, Nunes et al., 1992, Miranda et al., 1998), morphological (Searle, 1980) and magnetic isochron analysis (Luis et al., 1994) allow us to conclude that it roughly follows a narrow band aligned with the emplacement of the Azores Archipelago. This situation is kinematically described by global plate models (DeMets et al., 1990, 1994), which locate the present day EUR/AFR rotation pole at $21.0^{\circ} \mathrm{N}, 20.6^{\circ} \mathrm{W}$. For the Azores islands the NUVEL-1A model predicts relative motion of $4.2 \mathrm{~mm} / \mathrm{yr}$ toward $\mathrm{N} 70^{\circ} \mathrm{E}$. GPS observations for geodynamic studies have started in the Azores Archipelago in 1988 in the frame of the TANGO project (Trans-Atlantic Network for Geodynamics and Oceanography) (Bastos et al., 1991, 1998). In September-October 1999, 27 new sites, spread throughout the six islands of the central group of the Azores Archipelago, have been observed for the first time (Fernandes et al., 2000).

Results from the TANGO network have been already presented by Fernandes et al. (submitted) for the regional pattern of the displacement field. Within the accuracy of the available geodetic data, these authors conclude that the relative displacement between EUR and AFR along the Azores plate boundary is mostly accommodated within a relatively

Copy right(c) The Society of Geomagnetism and Earth, Planetary and Space Sciences (SGEPSS); The Seismological Society of Japan; The Volcanological Society of Japan; The Geodetic Society of Japan; The Japanese Society for Planetary Sciences. short lithospheric band that follows the islands emplacement and the neighbouring topographic ridges. End members of this system appear to be the S. Maria and Graciosa islands, which display pure "African" and "Eurasian" behaviour, respectively. All other sites are located along the presently active interplate deformation zone, showing an intermediate behaviour between the above end-members (Fernandes et al., submitted). This means that the EUR/AFR plate boundary must lie along the Azores Islands (east of the MAR). While geophysical and geodetic data seem to agree with the existence of a narrow active deformation area, there are large differences in the evaluation of relative displacement between the Azores Islands or within individual islands (Sigmundsson et al., 1995; Pagarete et al., 1998).

This study was developed in the scope of the STAMINA (Study of the Tectonic And Magmatic Interplay in the Azores) project. The main purpose of this project is to design a comprehensive model for the tectono-magmatic interplay in the Azores, mainly on the sector of the highest tectonic activity around the Terceira Axis, located between the East Graciosa Basin and the North Hirondelle Basin (Fig. 1), based on geophysical, geological, geodetic and geochemical data. In particular, this study focuses on the measurement of the present day deformation of the Terceira Island through a dense GPS network. Data from 10 stations in the Terceira Island were observed in 1999 and 2001. The displacement field between the two epochs is used to compute the local strain field. We show that, within the accuracy of the method, there is evidence for local rotation and horizontal compression in the NNE-SSW direction.

\section{Measurement Campaign and Additional Data}

The GPS network implemented on the Terceira Island consists of 23 stations distributed uniformly throughout the is- 


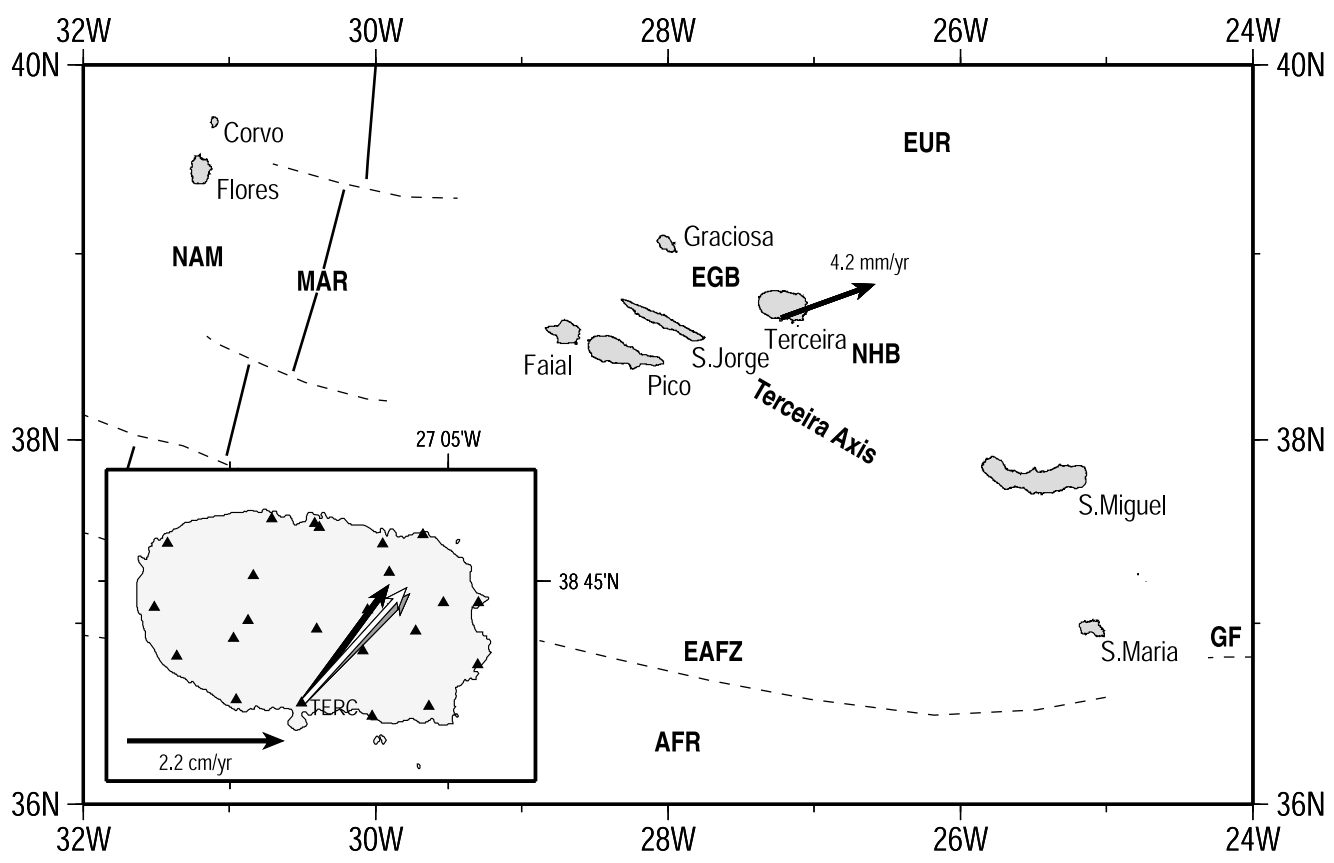

Fig. 1. Azores triple junction area (MAR - Mid-Atlantic Ridge, NAM-North-American plate, EUR - Eurasian plate, AFR - African plate, EAFZ - East Azores Fault Zone, GF-Gloria Fault, NHB - North Hirondelle Basin, EGB - East Graciosa Basin). Relative plate motion EUR/AFR is shown as a solid arrow according to Nuvel-1A (DeMets et al., 1994). Shown in the inset map is the stations distribution of the Terceira GPS network observed in 2001. TERC station absolute motion is shown as an open arrow according to Nuvel-1A (DeMets et al., 1994), as a solid arrow according to the ITRF and as a gray arrow according to DEOS2k (Fernandes et al., 2003).

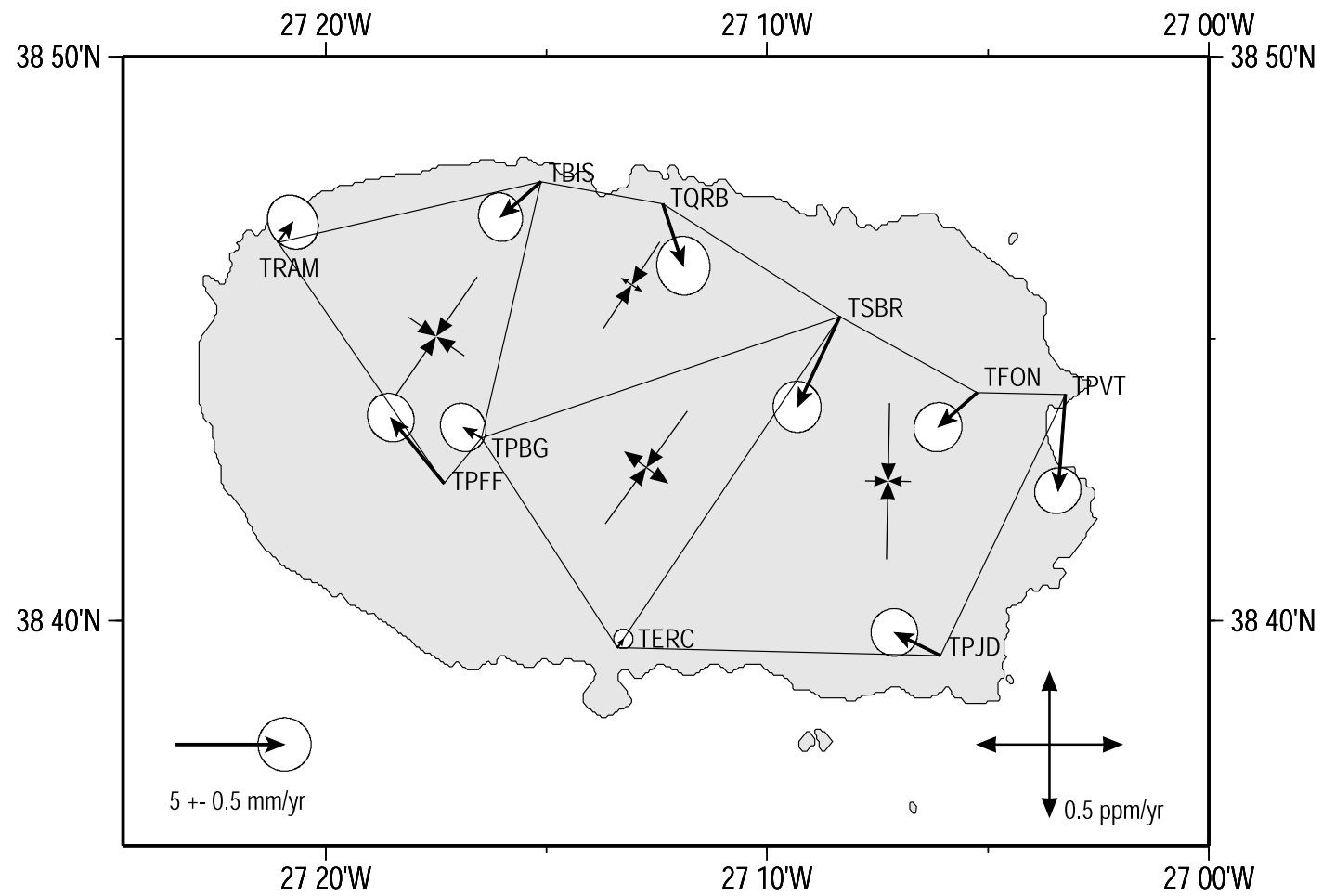

Fig. 2. Horizontal velocity vectors and error ellipses (95\% confidence level), from 1999.7 to 2001.3, relative to station TERC. Estimates of the strain rates for four sub-networks on the island. 1-sigma errors of the strain rates are smaller than $0.07 \mathrm{ppm} / \mathrm{yr}$ everywhere.

land (Fig. 1 inset). Ten of these stations were observed for the first time in September/October 1999. The second observation of the whole network was made in March/April 2001. Both campaigns lasted for nine days (days 270 to 278 in 1999 and days 90 to 98 in 2001).

The 1999 Terceira survey was conducted with Trimble
4000 SSI receivers and antennas, while the 2001 survey was conducted with both Trimble and Leica receivers and antennas. Antennas of the stations deployed on the island were fixed on central metallic screw-bolts cemented into solid outcrops that allow direct mounting of the GPS antennas. All receivers were programmed to record satellite phase and pseu- 


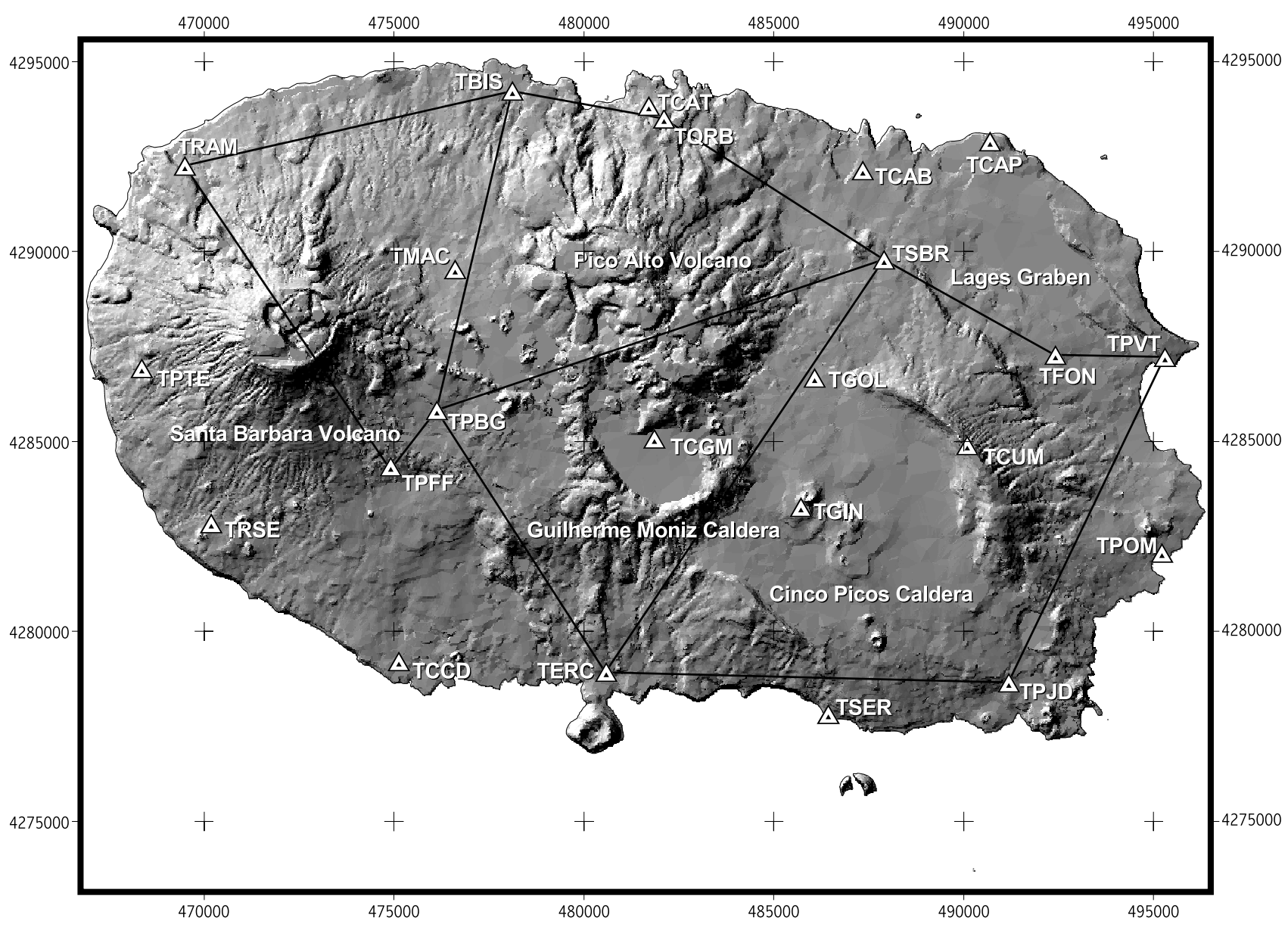

Fig. 3. Terceira Island Digital Terrain Model for the location of the main morphological volcanic structures of the island.

Table 1. Main characteristics of the 2 GPS campaigns performed on the Terceira Island in 1999 and 2001.

\begin{tabular}{lll}
\hline Campaign/ & 1999 Campaign & 2001 Campaign \\
$\begin{array}{l}\text { Description } \\
\text { Number of stations }\end{array}$ & 10 & 23 \\
Campaign duration & 9 days & 9 days \\
Receivers & Trimble 4000SSI & Trimble 4000SSI \\
& & Trimble 4000SSE \\
& & Leica SR520 \\
Number of sessions & 9 for TERC & 9 for TERC and TCAT \\
per station & 3 per station & 2 to 5 per station \\
Sessions duration & 24 hours & 12 hours (5 stations) \\
& 24 hours (18 stations) & \\
\hline
\end{tabular}

dorange data every 30 seconds, with the minimum number of satellites set to 4 and the minimum recording elevation mask set to 15 degrees.

In 1999, each station was observed for three sessions while in 2001 the number of sessions varies from two (three stations) to five (one station). Continuous measurements were made at station TERC (Fig. 2) over the nine days periods of the both campaigns. During the 2001 campaign, station TCAT (Fig. 3) was also recorded continuously. Those sites were used to link stations that were not occupied simultaneously. The initial idea was to collect 24 hours of continuous data at each station, however, due to some receiver malfunctions, the amount of recorded data varied from about 12 (five stations) to 24 (eighteen stations) hours. The main characteristics of both campaigns are summarised in Table 1 .

\section{GPS Data Processing}

The GPS data analysis was performed with the GAMIT software (King and Bock, 1999). Daily station positions for each campaign were estimated using the ionosphere-free linear combination as an observable and the ambiguities were resolved using ionospheric constraints and pseudorange data 


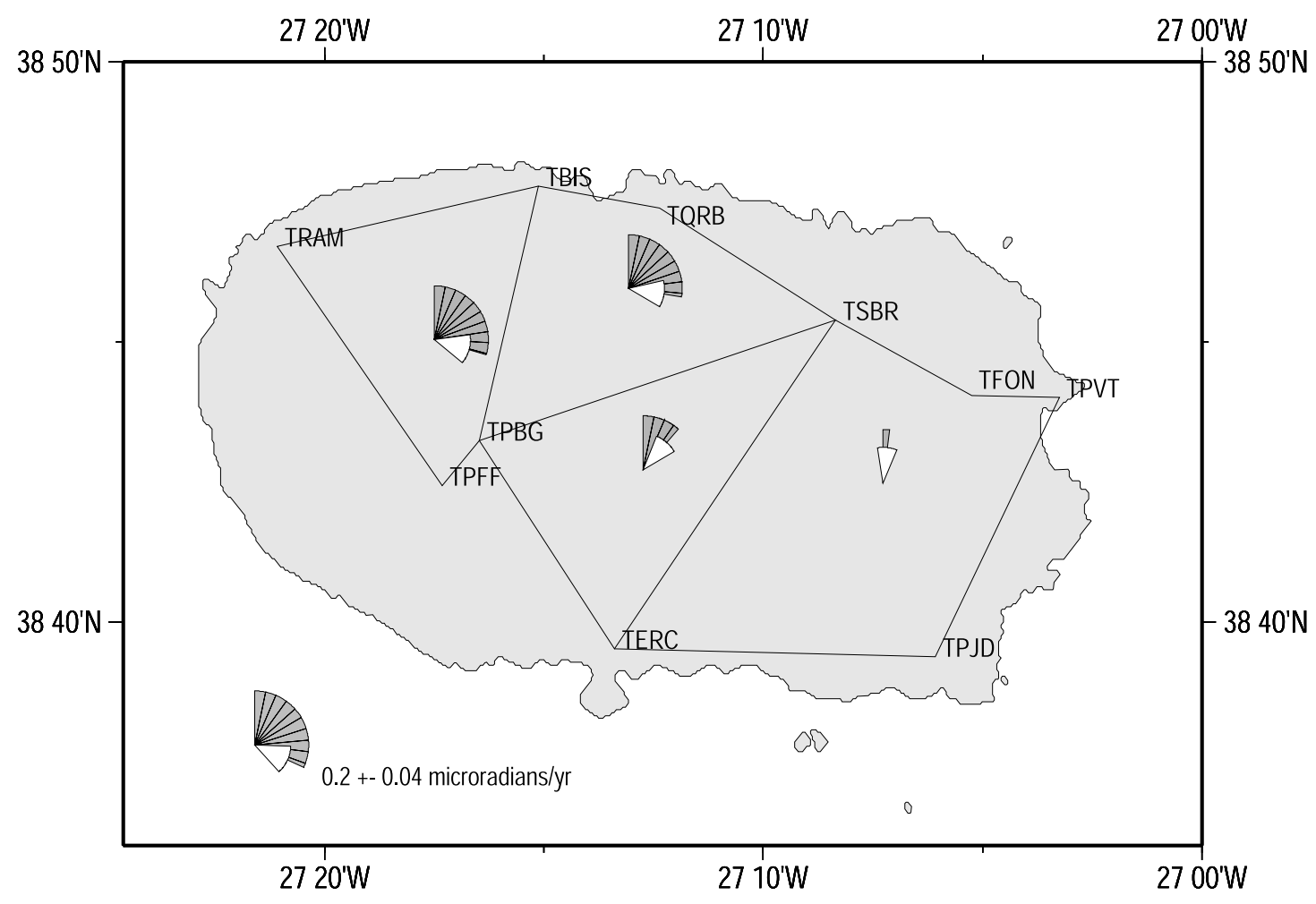

Fig. 4. Observed rates of local rotation, 1999 to 2001, for four sub-networks on the island, denoted by wedge symbols, which are oriented toward north and subtend an angle proportional to the observed rotation angle.

simultaneously. Approximate station positions and precise International GPS Service (IGS) combined orbits were used to derive solutions session by session. GPS data themselves were used to estimate tropospheric parameters for three-hour intervals. An elevation-dependent model was used for modelling the antenna phase centre variations.

The GPS network was referenced to the 1997 International Reference Frame (ITRF97) system, through the use of six IGS/EUREF permanent stations (Cape Canaveral3, Rabat, Savannah1, San Fernando, St. John's and Westerbork). The procedure was first to process the station TERC with the six permanent stations. Then, TERC was processed again, as a reference station, with the remaining stations of the local network (Navarro et al., 2002). TERC velocity in ITRF is shown in the Fig. 1 inset map. Absolute motion according to the DEOS2k (Fernandes et al., 2003) and NUVEL-1A (DeMets et al., 1994) models are also shown in the Fig. 1 inset map.

The three-dimensional network adjustment was performed using the FONDA software (Dong, 1993; Dong et al., 1998) designed for the estimation of geodetic parameters from space geodetic measurements. Daily solutions from both campaigns were combined to estimate station positions and velocities applying tight a priori constraints to all stations $(0.01 \mathrm{~m}$ and $0.005 \mathrm{~m} / \mathrm{yr})$ and even more tight constraints to the station TERC $(0.001 \mathrm{~m}$ and $0.001 \mathrm{~m} / \mathrm{yr})$. The related main strain and local rotation rates were also calculated using FONDA.

\section{Results of GPS Measurements}

Site coordinate repeatability (i.e. the root-mean-squares of the daily independent solutions about their mean value) was calculated to evaluate the measurement precision for both campaigns. The uncertainties for horizontal components are around $3 \mathrm{~mm}$ and $2 \mathrm{~mm}$, respectively, for the 1999 and 2001 data. Horizontal position uncertainties are slightly better for 2001. However, the values of $5.4 \mathrm{~mm}$ and $6 \mathrm{~mm}$ were found for the vertical position in 1999 and 2001, respectively. This probably reflects the fact that in 1999 we used the same type of antennas for all the sites.

The comparison between the 1999 and 2001 coordinates shows that the horizontal displacements, measured in the one and a half year interval, are at the mm level (Fig. 2). Horizontal velocity vectors vary from 1 (TPBG) to 4.6 (TSBR) $\mathrm{mm} / \mathrm{yr}$. The $95 \%$ confidence error ellipses are almost circular with an average radius of $0.4 \mathrm{~mm}$. Although the displacements are small, they exceed the $95 \%$ confidence limits, except for stations TRAM and TPBG.

A strain analysis, for the same period, was performed for four sub-networks to evaluate the direction of extension (Fig. 2). The algorithm is based on the method of simultaneous adjustment proposed by Bibby (1982), and described by Snay et al. (1983), Snay (1986) and Drew and Snay (1989). The algorithm adopts a linear model to calculate both strain and local rotation rates of a specified sub-network, based on the components of the velocity vector of each station of the sub-network. The definitions of the estimated parameters for the network are given in detail in Feigl et al. (1990).

The four sub-networks were chosen based on the location of the main morphological volcanic structures of the island. The western sub-network covers partially the Santa Barbara volcano, which is the youngest volcanic feature on the island (Fig. 3). The eastern sub-network covers totally the Cinco Picos caldera, which is the oldest caldera in the island. The up- 
per central sub-network covers the Pico Alto volcano while the lower one covers the Guilherme Moniz caldera. There is another major structure, the Lages graben, which is not covered by the 10 stations network.

Strain rates in the direction of the principal axis $\varepsilon_{1}$ (orientation of the maximum extension rate) exhibit negative values for 2 sub-networks, ranging from $-0.19 \pm 0.06 \mu$ strain/yr to $-0.13 \pm 0.04 \mu$ strain $/ \mathrm{yr}$, and positive values for the other two sub-networks, ranging from $0.07 \pm 0.05 \mu$ strain/yr to $0.15 \pm 0.06 \mu$ strain/yr, while strain rates in the direction of $\varepsilon_{2}$ exhibit a mean negative value of $-0.38 \pm 0.05 \mu$ strain $/ \mathrm{yr}$. The associated 1-sigma errors are smaller than $0.07 \mathrm{ppm} / \mathrm{yr}$. These results indicate that the extension is positive only for the two sub-networks in the central part of the island. For the other two sub-networks, located on the E-W edges of the island, there is compression in both directions. The orientation of the maximum compressive strain rate, $\varepsilon_{2}$, is around N35 $\pm 7^{\circ} \mathrm{E}$ for the three sub-networks on the western part of the island and $\mathrm{N} 1 \pm 5^{\circ} \mathrm{E}$ for the eastern sub-network. An areal contraction $\left(\varepsilon_{1}+\varepsilon_{2}\right)$ of around $-0.40 \pm 0.07 \mu$ strain/yr was found for the island (significant at the $95 \%$ confidence level), not reproducing at the Island level the transtensive regime precluded by the NUVEL-1A behaviour for the EUR/AFR boundary shown in Fig. 1.

The local rotation rates derived from the horizontal velocity vectors for each sub-network are exhibited in Fig. 4. The mean value of $0.14 \pm 0.04 \mu \mathrm{radians} / \mathrm{yr}$ and the value of $0.01 \pm 0.03 \mu$ radians/yr were obtained for the three western sub-networks and for the eastern sub-network, respectively.

\section{Discussion and Conclusions}

Crustal displacements and strain rates for the Terceira Island were derived from the observation of 10 stations of a dense GPS network. Two GPS campaigns over one and a half year period span allowed us to determine small but significant motions within the Terceira Island. Areal compression was found for four sub-networks considered on the island. The rate of local rotation is consistent in the western part of the island while no differential rotation was found in the eastern part. Although these results are significant at the 95\% confidence level and regional coherence of the velocity field and strain rates field (Fig. 2) is observed, they must be considered with care once the displacements observed in the Azores are rather small (less than $5 \mathrm{~mm}$ ) and only two campaigns have been completed.

The first comment must be made to the existence of two domains, one trending WNW corresponding to the western part of the Terceira Island, and the other, located eastward, even though the boundary between the two domains cannot be clearly identified from the present configuration of the observation network. This is suggested based on the similarity of the strain and local rotation rates for the three subnetworks located on the western side of the island. The second comment relates with the observation of areal compression in an environment dominated by a transtensive tectonic regime. This situation is unexpected, and if confirmed by further observations, we need to find its explanation in the complexity of the volcanic and tectonic processes that, at the local scale, contribute to the global extension of the Terceira Axis.
It should be emphasized that a problem exists in matching current day plate boundary configuration from GPS measurements with the long-term average plate movements over the past $3 \mathrm{Ma}$ largely based on marine magnetic anomalies (DeMets et al., 1994). The short time span covered by the GPS measurements, implies that interpretations can be highly susceptible to change due to local variations of the strain pattern, as a response to specific geologic events. With this regard, factors such as fault locking during interseismic periods, coseismic deformation and swarm activity, not necessarily coexisting with expressed volcanic phenomena, can all be accounted for, as transtensive strain, thus controlling the configuration and mechanics of the inter-plate deformation zone.

Finally, differential rotation rates, depicted in Fig. 4, are in conformity with previous morphological and seismicity analysis (Miranda et al., 1998). As proposed by Miranda et al. (1998), two conjugate families of faults define a group of "blocks" that coincide with the topographic anomaly of the Azores plateau and are bounded in the north and south by N120E right-lateral faults (sub-parallel to the transform faults in the Azores area) and in the west and east by N150E left-lateral faults. The blocks can either move relative to each other, when the N120E faults are active, or rotate clockwise if the N150E faults are active. Although the estimated rotation rates are just confined to a small segment of the Azores region, results suggest a new insight into the study of its deformation pattern. The observation of a larger number of stations uniformly distributed throughout the island, and a longer time span of the GPS observations are required to better constrain the displacements rates. The re-observations of the entire network, in the near future, will allow a more reliable determination of the deformation field.

Acknowledgments. We are grateful to the Instituto Geográfico Português, to the Instituto de Investigação Científica Tropical, to the Observatório Astronómico da Universidade do Porto and to the Delft Institute for Earth-Oriented Space Research for supplying most of the GPS receivers and antennas used during the Terceira 2001 campaign. We also thank to Dra. Luísa Bastos for the GPS data acquired in 1999 in the scope of the TANGO project. A special thank to Bob King who kindly clarified some questions concerning the GPS data processing. This work was funded by FCT (Portuguese Foundation for Sciences and Technology) through STAMINA project (PDCTM1999MAR15255).

\section{References}

Bastos, L., J. Osório, H. Landau, and G. Hein, The Azores Arquipelago GPS network, Life and Earth Sciences, 9, 1-9, 1991.

Bastos, L., J. Osório, A. Barbeito, and G. Hein, Results from geodetic measurements in the western part of the African-Eurasian plate boundary, Tectonophysics, 294, 261-269, 1998.

Bibby, H. M., Unbiased estimate of strain from triangulation data using the method of simultaneous reduction, Tectonophysics, 82, 161-174, 1982.

Buforn, E., A. Udias, and M. A. Colombas, Seismicity source mechanisms and tectonics of the Azores-Gibraltar plate boundary, Tectonophysics, 152, 89-118, 1988.

DeMets, C., R. G. Gordon, D. F. Argus, and S. Stein, Current plate motions, Geophysical Journal International, 101, 425-478, 1990.

DeMets, C., R. G. Gordon, D. F. Argus, and S. Stein, Effect of recent revisions to the magnetic reversal time scale on estimates of current plate motions, Geophysical Research Letters, 21, 2191-2194, 1994.

Dong, D., The horizontal velocity field in southern California from a combination of terrestrial and space-geodetic data, Ph.D Thesis, Massachusetts Institute of Technology, Cambridge, 1993.

Dong, D., T. A. Herring, and R. W. King, Estimating crustal deforma- 
tion from a combination of terrestrial and space-based data, Journal of Geodesy, 72(4), 200-214, 1998.

Drew, A. R. and R. A. Snay, DYNAP: Software for estimating crustal deformation from geodetic data, Tectonophysics, 162, 331-343, 1989.

Feigl, K., R. W. King, and T. H. Jordan, Geodetic measurement of tectonic deformation in the Santa Maria fold and Thrust Belt, California, Journal of Geophysical Research, 95(B3), 2679-2699, 1990.

Fernandes, R. M. S., L. Bastos, B. Ambrosius, J. Osório, and P. Baptista, The TANGO99 GPS campaign: Description and results, Proceedings of the 2nd Portuguese-Spanish Assembly of Geodesy and Geophysics, Lagos, Portugal, 35-37, 2000.

Fernandes, R. M. S., B. A. C. Ambrosius, R. Noomen, L. Bastos, M. J. R. Wortel, W. Spakman, and R. Govers, The relative motion between Africa and Eurasia as derived from ITRF2000 and GPS data, Geophysics Research Letters, 30(16), doi:10.1029/2003GL017089, 2003.

Fernandes, R. M. S., L. Bastos, J. M. Miranda, N. Lourenco, B. A. C. Ambrosius, R. Noomen, and W. Simons, Defining the Plate Boundaries in the Azores Region, Journal of Volcanology and Geothermal Research, 2003 (submitted).

Grimison, N. L. and W. P. Chen, The Azores-Gibraltar plate boundary: Focal mechanism, depths of earthquakes and their tectonic implications, Journal of Geophysical Research, 91(B2), 2029-2047, 1986.

Grimison, N. L. and W. P. Chen, Source mechanisms of four recent earthquakes along the Azores-Gibraltar plate boundary, Geophysical Journal International, 92, 391-401, 1988.

King, R. W. and Y. Bock, Documentation for the GAMIT GPS software analysis version 9.9, Massachusetts Institute of Technology, Cambridge, 1999.

Luis, J., J. M. Miranda, P. Patriat, A. Galdeano, J. C. Rossignol, and L. A Mendes Victor, Açores Triple Junction evolution in the last $10 \mathrm{Ma}$ from a new aeromagnetic survey, Earth and Planetary Sciences Letters, 125 439-459, 1994.

Miranda, J. M., L. A. Mendes Victor, J. Simões, J. Luís, L. Matias, H.
Shimamura, H. Shiobara, H. Nemoto, H. Mochizuki, A. Hirn, and J. Lépine, Tectonic setting of the Azores Plateau deduced from a OBS survey, Marine Geophysics Researches, 20(3), 171-182, 1998.

Navarro, A., J. Catalão, and J. M. Miranda, Comparison between different approaches to GPS data processing: a case study in the Terceira Island, Proceedings of the 3rd Portuguese-Spanish Assembly of Geodesy and Geophysics, Vol. 1, 344-345, Valencia, Spain, 2002.

Nunes, J. C., J. L. Alves, and V. H. Forjaz, Sismicidade instrumental dos Açores no período 1980-89: Implicações neotectónicas, S.R.H.O.P. dos Açores e L.N.E.C., Vol. 1, 141-160, 1992.

Pagarete, J., J. Teixeira Pinto, V. B. Mendes, C. Antunes, and H. Ribeiro, The importance of classical geodetic observations for analyzing the geodynamic behaviour of the Açores Archipelago, Tectonophysics, 294(3-4), 281-290, 1998.

Searle, R. C., Tectonic pattern of the Azores spreading center and triple junction, Earth and Planetary Sciences Letters, 51, 415-434, 1980.

Sigmundsson, F., E. Tryggvason, M. M. Alves, J. L. Alves, K. Pálsson, and H. Olafsson, Slow inflation of the Furnas volcano, São Miguel, Azores, suggested from initial levelling and Global Positioning System measurements, Geophysical Research Letters, 22(13), 1681-1684, 1995.

Snay, R. A., Horizontal deformation in New York and Connecticut: Examining contradictory results from the geodetic evidence, Journal of Geophysical Research, 91, 12,695-12,702, 1986

Snay, R. A., M. W. Cline, and E. L. Timmerman, Regional deformation of the earth model for the San Diego Region, California, Journal of Geophysical Research, 88, 5009-5024, 1983.

Udias, A., A. Lopez Arroyo, and J. Mezcua, Seismotectonic of the Azores Alborean region, Tectonophysics, 31, 259-289, 1976.

A. Navarro (e-mail: anavarro@fc.ul.pt), J. Catalão, J. M. Miranda, and R. M. Fernandes 